\title{
PROPOSIÇÃO DE MODELO PARA MEDIR O NÍVEL DE MATURIDADE DE RELACIONAMENTOS ENTRE PARTICIPANTES DE UMA CADEIA DE SUPRIMENTO
}

\section{A MODEL FOR MEASURING THE MATURITY LEVEL OF THE RELATIONSHIP BETWEEN PARTICIPANTS OF A SUPPLY CHAIN}

\author{
Gilberto Zanoni ${ }^{1}$; Edson Pinheiro de Lima ${ }^{2}$; Sérgio Eduardo Gouvêa da Costa ${ }^{3}$ \\ ${ }^{1}$ Programa de Pós-Graduação em Engenharia de Produção e Sistemas - PPGEPS - Pontifícia \\ Universidade Católica do Paraná - PUCPR - Curitiba - Paraná - Brasil zanoni@superig.com.br \\ ${ }^{2}$ Dr. Eng. - Programa de Pós-Graduação em Engenharia de Produção e Sistemas - PPGEPS - \\ Pontifícia Universidade Católica do Paraná - PUCPR - Curitiba - Paraná - Brasil \\ e.pinheiro@pucpr.br \\ ${ }^{3}$ Dr. Eng. - Programa de Pós-Graduação em Engenharia de Produção e Sistemas - PPGEPS -
} Pontifícia Universidade Católica do Paraná - PUCPR - Curitiba - Paraná - Brasil s.gouvea@pucpr.br

\begin{abstract}
Resumo
Atualmente, a competitividade no meio empresarial se apresenta no âmbito da cadeia de suprimento. A integração estratégica de processos e de atividades entre os membros de uma cadeia de suprimento tornam-se fatores-chave de sucesso. Fundamentando-se na evolução conceitual da logística obtém-se a evolução dos relacionamentos entre os membros de uma cadeia de suprimento. Combinando modelos de sistemas de medição do desempenho desenvolveu-se uma matriz que poderá ser utilizada para medir os níveis de maturidade de relacionamentos entre participantes de uma cadeia de suprimento. Este artigo apresenta uma contribuição teórico-conceitual, propondo um modelo referencial para análise de níveis de maturidade do relacionamento entre membros de uma cadeia de suprimento. $O$ modelo referencial combina sistemas de medição do desempenho e estabelece como níveis de maturidade as definições de Cadeia de Suprimento (CS), Gerenciamento da Cadeia de Suprimento (GCS) e de Gerenciamento da Cadeia de Suprimento Ampliada, formulada a partir da definição de Empresa Ampliada (EA).
\end{abstract}

Palavras-chave: evolução conceitual da logística; sistemas de medição do desempenho; níveis de maturidade de relacionamentos; gerenciamento da cadeia de suprimento ampliada.

\section{Introdução}

Considerando um ambiente competitivo global, constata-se que os mercados em todos os setores estão ficando muito mais exigentes. Isso resulta na necessidade de empresas unirem esforços, formando cadeias através de parcerias entre fornecedores, fabricantes e distribuidores, para produzir bens e serviços que agreguem valor para o consumidor final. 
Para tanto, estas empresas estão em constante evolução buscando melhorar o nível de relacionamento entre todos os participantes da cadeia, visando atender às necessidades de seus clientes finais e, desta forma, prosperar e garantir a sobrevivência nos mercados em que atuam. Dentro desse contexto, o presente estudo pretende responder ao seguinte questionamento: Como medir o nível de maturidade do relacionamento entre participantes de uma cadeia de suprimento, combinando modelos de medição de desempenho e, considerandose ainda, os níveis de maturidade a partir da evolução conceitual da logística e das definições de cadeia de suprimento, gerenciamento da cadeia de suprimento e de empresa ampliada? Para responder a esta pergunta, o presente estudo tem como objetivo desenvolver um modelo conceitual que seja apropriado para medir o nível de maturidade do relacionamento entre os membros de uma cadeia de suprimento (CS). As proposições básicas deste estudo dizem respeito a apresentar a evolução conceitual da logística, combinar sistemas de medição do desempenho para desenvolver um modelo conceitual para medir níveis de maturidade de relacionamentos entre participantes de uma cadeia de suprimento e analisar o modelo proposto. Este trabalho foi estruturado da seguinte forma: a primeira seção traz uma introdução ao trabalho. A segunda seção exibe a investigação na literatura sobre a evolução conceitual da logística, definições de Cadeia de Suprimento (CS), Gerenciamento da Cadeia de Suprimento (GCS), Empresa Ampliada (EA) e de Sistemas de Medição do Desempenho (SMD). A terceira seção apresenta e analisa o modelo proposto para medir níveis de maturidade do relacionamento entre participantes de uma cadeia de suprimento. Finalmente, faz-se uma análise crítica do exercício e resultados para se chegar às conclusões e recomendações.

\section{Desenvolvimento do modelo de análise}

O desenvolvimento do modelo de análise dos níveis de maturidade dos participantes de uma cadeia de suprimento dar-se-á através de uma breve revisão na literatura sobre a evolução conceitual da logística apresentada por Boyson et. al., (1999), das definições de cadeia de suprimento (CS), de gerenciamento da cadeia de suprimento (GCS), de empresa ampliada (EA) e da combinação de sistemas de medição do desempenho (SMD), do Prisma de Neely et. al., (2000) e do modelo SCOR - Supply Chain Operations Reference, que Harrison e Hoek (2003) consideram como modelo de referência das operações na CS.

\subsection{A evolução conceitual da logística}

A evolução conceitual da Logística, proposta por Boyson et al., (1999), subdivide-se em quatro estágios evolutivos distintos, no que se refere ao processo de evolução da cadeia de 
suprimento (CS). Ampliando esta evolução conceitual, foi acrescentado um quinto estágio, o qual adota a definição de Gerenciamento da Cadeia de Suprimento Ampliada (GCSA), desenvolvida a partir do conceito de empresa ampliada (EA), formulado por Bititci et. al., (2005), que analisaremos a seguir:

I. Estágio 1 - Logística Subdesenvolvida: após a segunda guerra mundial até a década de 70, as atividades de logística focavam a eficiência da distribuição física dentro das atividades de transporte, armazenagem, controle de inventário, processamento de pedidos e expedição.

II. Estágio 2 - Logística Incipiente: nos anos 80, o foco foi a integração entre as funções de logística, a fim de maximizar sua eficiência. Ênfase no transporte e na armazenagem.

III. Estágio 3 - Logística Interna Integrada: na década passada, surgiram novos canais de distribuição e novos conceitos de processo produtivo. Busca da competitividade através da adoção de métodos quantitativos de controle de qualidade, da oferta de serviços aos clientes, da formulação de equipes internas interfuncionais e na segmentação da base da cadeia.

IV. Estágio 4 - Logística Externa Integrada: nesta década tem-se verificado uma maior preocupação com as interfaces entre os integrantes da cadeia de suprimentos. Foco no aprimoramento da previsão de demanda e no planejamento colaborativo entre os elos da cadeia de suprimentos. Investimentos em sistemas de compartilhamento de informação para gerir os elos da cadeia.

IV. Estágio 5 - Logística de cooperação e integrada através da cadeia de valor: paralelamente ao estágio 4, tem-se verificado que uma cadeia de empresas está se comportando essencialmente como uma única empresa. Daí surge a necessidade do Gerenciamento da Cadeia de Suprimento Ampliada. As organizações buscam parcerias e estes parceiros não devem ser vistos como subcontratados, mas como verdadeiros parceiros na cadeia de valor ampliada. (Christopher, 2002). O foco está baseado no conhecimento. No uso das potencialidades, competências e das forças intelectuais de seus membros para 
ganhar a vantagem competitiva e maximizar o desempenho total, assim otimizar o desempenho de cada empresa individual. (Bititci, 2005).

Figura 1- Estágios Organizacionais de Crescimento

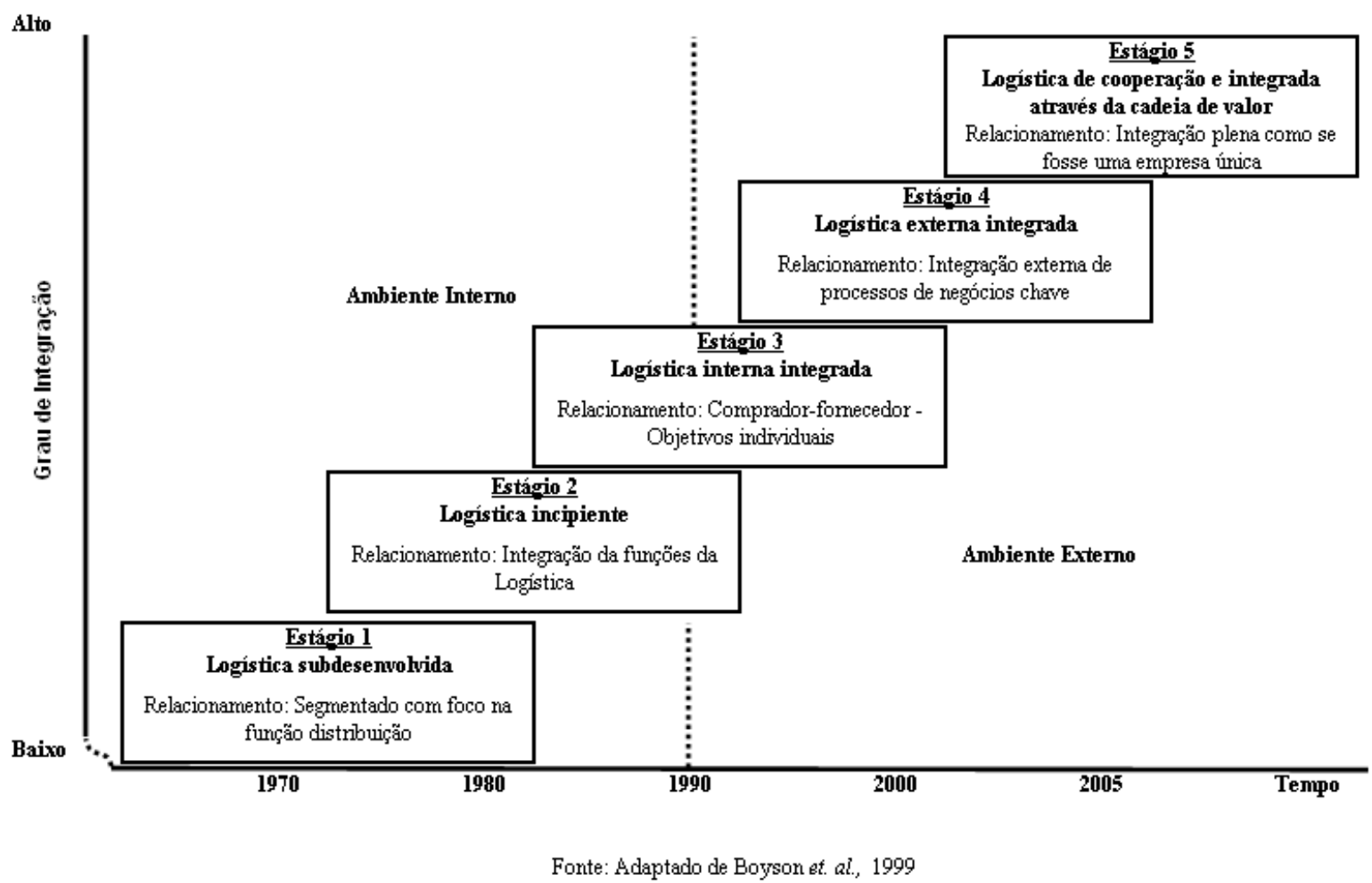

A importância deste estudo fica evidente no reconhecimento da importância do estudo da evolução conceitual da logística e especificamente a análise da evolução dos relacionamentos entre membros de uma cadeia de suprimento (CS) como fator de aquisição de vantagem competitiva, presente em todas os estágios desta evolução.

\subsection{Da cadeia de suprimento ao gerenciamento da cadeia de suprimento ampliada}

Com base no estudo da evolução conceitual da logística e considerando-se as definições de cadeia de suprimento (CS), gerenciamento da cadeia de suprimento (GCS) e de gerenciamento da cadeia de suprimento ampliada (GCSA), propor-se-á os níveis de maturidade de relacionamento entre participantes de uma CS.

\subsubsection{Definições de cadeia de suprimento}

Para o Supply Chain Council, CS é uma estrutura que abrange todos os esforços envolvidos na produção e liberação de um produto final, desde o (primeiro) fornecedor do fornecedor até o (último) cliente do cliente. Quatro processos básicos definem esses esforços, que são: o Planejar (Plan), o Abastecer (Source), o Fazer (Make) e o entregar (Delivery). 
Lambert et al., (1998) lembram que mais estritamente falando, uma CS não é apenas uma cadeia de negócios com relacionamentos "um a um", mas sim uma rede de múltiplos negócios e relações.

Mentezer et al., (2001) definem uma CS como o conjunto de três ou mais entidades diretamente envolvidas nos fluxos a montante ou a jusante de produtos, serviços, financeiro e de informação, desde a fonte de matéria-prima até o cliente final.

Pires (2004) define uma CS como uma rede de companhias autônomas, ou semiautônomas, que são efetivamente responsáveis pela obtenção, produção e liberação de um determinado produto e/ou serviço ao cliente final.

Já, Para Bititci et al., (2005) CS é uma cadeia de empresas individuais, composta pela relação entre clientes e fornecedores, que opera como uma empresa individual que tenta maximizar seus próprios objetivos e, dessa forma, sub-otimizando o desempenho total, conforme ilustra a figura 2 .

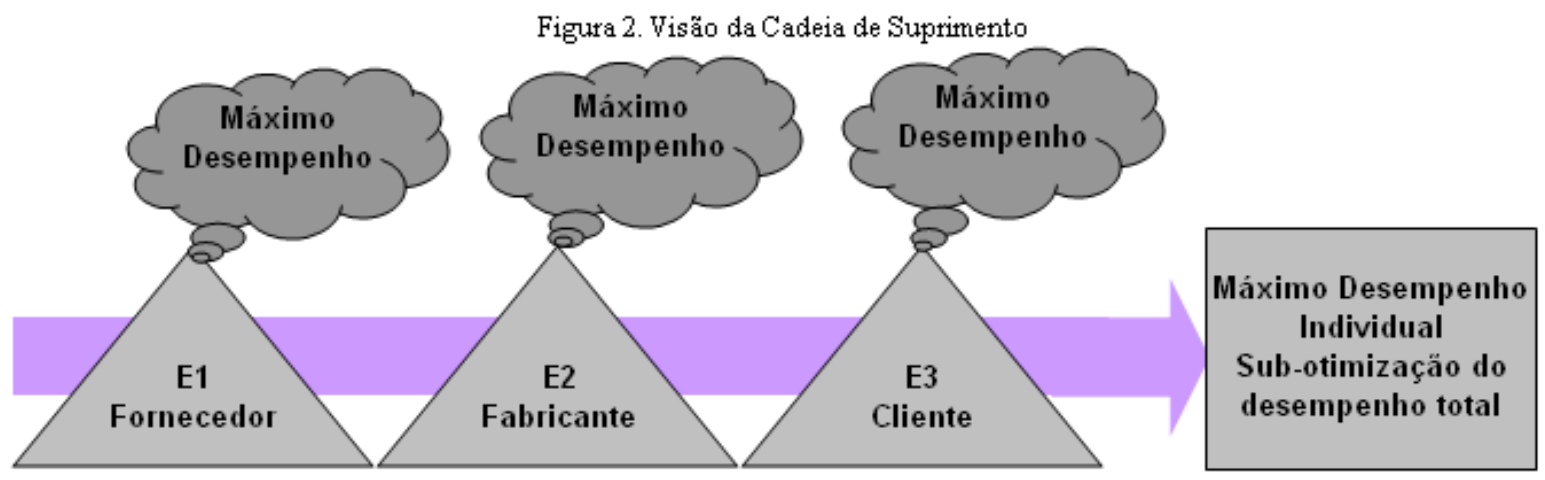

Fonte: Adaptado de Bititci et. al., 2005

\subsubsection{Distinção e definições de logística e de gerenciamento da cadeia de suprimento (GCS)}

\subsubsection{Distinção entre logística e GCS}

Desde o seu surgimento, o GCS tem muitas vezes sido confundido com a logística, seja na indústria, na consultoria ou na academia. Cooper et. al., (1997) relatam que executivos de corporações líderes em seus segmentos e que têm implementado o estado-da-arte em GCS entendem que ela abrange um escopo maior de processos e funções que a logística. Lembram 
também, que, em 1998, o Council of logistics Management (CLM), com o intuito de esclarecer a confusão, modificou sua definição de logística para indicar que ela é um subconjunto (subset) da GCS e que os dois termos não são sinônimos. Assim, o CLM estipulou que:

"Logística é a parte dos processos da cadeia de suprimentos (CS) que planeja, implementa e controla o efetivo fluxo e estocagem de bens, serviços e informações correlatas desde o ponto de origem até o ponto de consumo, com o objetivo de atender as necessidades do cliente".

\subsubsection{Definições de GCS}

O Global Supply Chain Fórum (GSCF), definiu que:

"GCS é a integração dos processos de negócios desde o usuário final até os fornecedores originais (primários) que providenciam produtos, serviços e informações que adicionam valor para os clientes e stakeholders".

Lambert et. al., (1998) implicitamente também compartilham com a definição do GSCF ao afirmar que GCS é a integração dos processos de negócios chaves desde o usuário final até os fornecedores originais (primários) que providenciam produtos, serviços e informações que adicionam valor para os clientes e para outros stakeholders.

Segundo Mentzer et al., (2001), GSC é o conjunto de três ou mais entidades diretamente envolvidas nos fluxos anteriores e posteriores dos produtos, serviços, finanças e/ou informações desde o ponto de origem até o consumidor.

Novaes (2001) apresenta a definição formulada no fórum de GCS realizado na Ohio State Universety que á a seguinte:

"GCS é a integração dos processos industriais e comerciais, partindo do consumidor final indo até os fornecedores, iniciais, gerando produtos, serviços e informações que agreguem valor para o cliente". 
Pires (2004) definiu GCS como sendo um modelo gerencial que busca obter sinergias através da integração dos processos de negócios chaves ao longo da cadeia de suprimentos, cujo objetivo principal é atender ao consumidor final e outros stakeholders da forma mais eficaz e eficiente possível, ou seja, com produtos e/ou serviços de maior valor percebido pelo cliente final e obtido através do menor custo possível.

\subsubsection{Definições de empresa ampliada (EA) e de gerenciamento da cadeia de suprimento ampliada (GCSA)}

De acordo com Martinez et al., (2001) e Kochhar e Zhang, (2002) EA é uma filosofia onde membros de organizações estrategicamente combinam suas competências centrais e capacidades para criar uma competência única. Um aspecto disso é o desenvolvimento de produtos e serviços que melhor se encaixam nas características físicas e intelectuais dos mercados individuais.

A formulação estratégica de negócio da EA é um processo incrementado; planejamento, implementação, avaliação e revisão representam pequenos passos, feitos quase que simultaneamente. (Martinez et. al., 2001; Lillehagen and Karlsen, 2001).

Nas EA's, as pessoas através de várias organizações participam nos processos de tomada de decisões. Isto demanda integração de conhecimento, o que inclusive significa uma mudança mais profunda nas estruturas de poder das organizações envolvidas. Por esse motivo, a melhora nos níveis de educação, desenvolvimento, participação, atitudes cívicas e de melhoria da comunicação são pré-requisitos para operação efetiva das EA. (O’Neill and Sackett, 1994)

Para Martinez et al., (2001) uma EA impõe uma estrutura geral para comunicação e sincronia entre empresas individuais.

Segundo Bititci et al., (2005) uma EA é uma cadeia de empresas, que se comportam essencialmente como uma única empresa que tenta maximizar os objetivos corporativos, assim otimizando o desempenho de cada empresa individual.

Diante das definições de EA, apresentadas anteriormente, conclui-se que o Gerenciamento da Cadeia de Suprimento Ampliada (GCSA) está baseado no conhecimento, 
no uso das potencialidades, competências e forças intelectuais de seus membros para ganhar a vantagem competitiva e maximizar o desempenho total.

As operações, no gerenciamento da cadeia de suprimento ampliada (GCSA), precisam ser cuidadosamente coordenadas e sincronizadas como se fosse um processo dentro de uma única empresa. Isto irá envolver pessoas multi-qualificadas e multi-culturais trabalhando em diferentes empresas. $\mathrm{O}$ uso de um plano apropriado e a coordenação de sistema e ferramentas suportam facilidades de comunicação - as quais irão permitir aos membros das equipes dividir informação e sincronizar as atividades -, são também pré-requisitos críticos (O’Neill and Sackett, 1994). Os relacionamentos entre membros de uma EA devem ser de longo prazo com um número limitado de fornecedores que trabalham na base da confiança mútua.

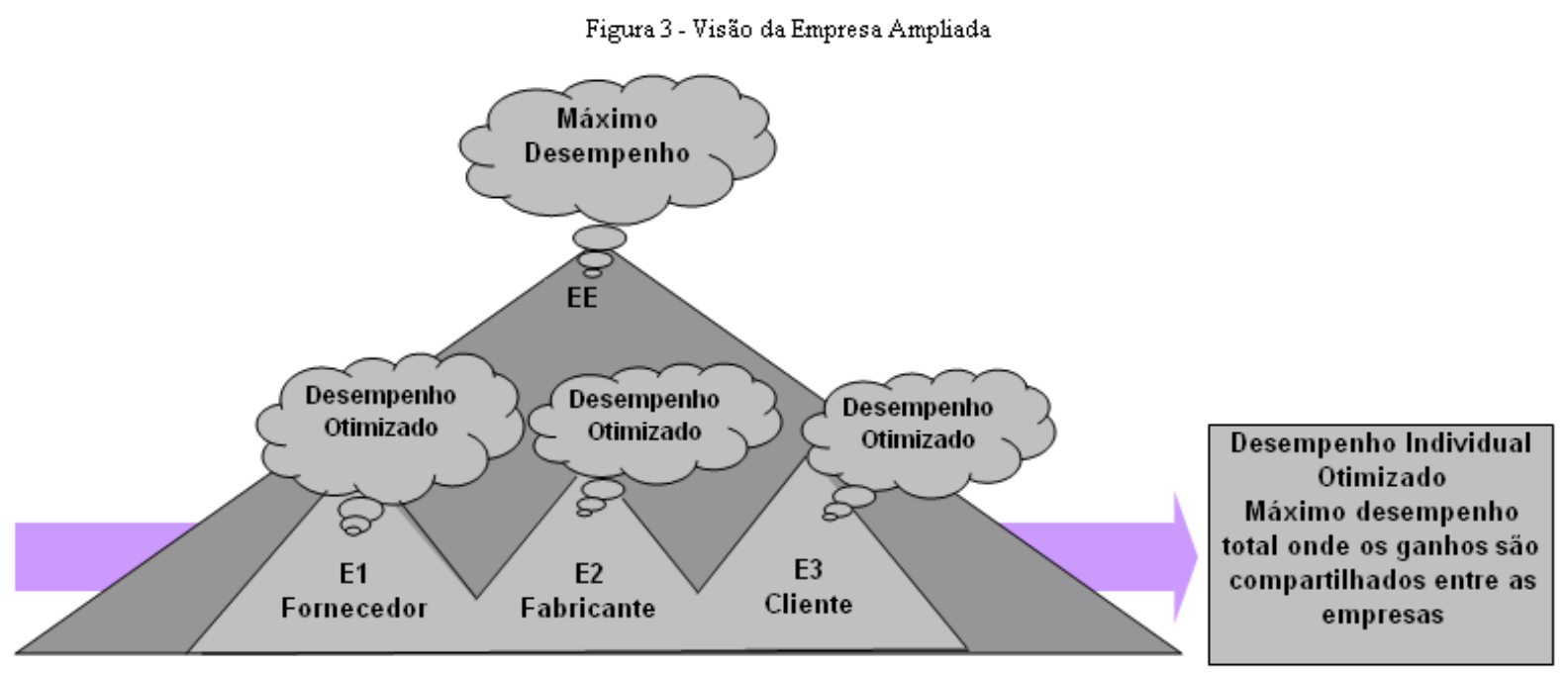

Fonte: Adaptado de Bititci et. al. , 2005

\subsection{Definições de níveis de maturidade de relacionamentos}

Com base na breve revisão na literatura sobre a evolução conceitual da logística, das definições de CS, GCS, EA, GCSA e, considerando a distinção entre Logística e GCS, para os propósitos deste estudo, optou-se por determinar os níveis de maturidade de relacionamentos entre membros de uma CS a partir das definições apresentadas a seguir:

- $\quad$ Nível 1 - definição de CS, formulada por Bititci, (2005);

"CS é uma cadeia de empresas individuais, clientes-fornecedores, que operamse como uma empresa individual que tenta maximizar seus próprios objetivos, assim sub-otimizando o desempenho total". 
- $\quad$ Nível 2 - definição de GCS, formulada por Pires, (2004);

"GCS é um modelo gerencial que busca obter sinergias através da integração dos processos de negócios chaves ao longo da cadeia de suprimentos, cujo objetivo principal é atender ao consumidor final e outros stakeholders da forma mais eficaz e eficiente possível, ou seja, com produtos e/ou serviços de maior valor percebido pelo cliente final e obtido através do menor custo possível".

- $\quad$ Nível 3 - definições, de EA formulada por Bititci (2005), e de GCSA.

"Uma EA é uma cadeia de empresas, que se comportam essencialmente como uma única empresa que tenta maximizar os objetivos corporativos, assim otimizando o desempenho de cada empresa individual".

"Gerenciamento da Cadeia de Suprimento Ampliada (GCSA) está baseado no conhecimento, no uso das potencialidades, competências e forças intelectuais de seus membros para ganhar a vantagem competitiva e maximizar o desempenho total".

\subsection{Sistemas de medição de desempenho}

Os gestores de hoje enfrentam o desafio de apresentar bom desempenho em toda uma variedade de objetivos, conforme comentam Harrison e Roek (2003). Os diferentes grupos de interessados em uma organização incluem os acionistas, os funcionários, os fornecedores, a comunidade local e o governo. Essa não é uma lista abrangente, e indústrias de diversos setores possuem outros interessados importantes como, por exemplo, entidades reguladoras. O desafio destes gestores é equilibrar os diversos interesses desses grupos de interessados. Assim, os diretores de uma empresa enfrentam a necessidade de gerenciar os interesses potencialmente conflituosos dos envolvidos, mantendo cada um deles dentro do que Doyle, (1994) chama de "zona de tolerância". Cada envolvido possui um limite, além do qual o risco de conturbações para os negócios aumenta rapidamente. Também existe um limite superior. Por exemplo, uma preocupação com lucros pode agradar os acionistas neste exato momento, mas pode resultar em pontos negativos, como a exploração da mão-de-obra e baixos níveis de investimentos. Apesar de lucros vultuosos aparecerem no primeiro ano, eles são rapidamente 
erodidos à medida que os pontos negativos começam a surgir em anos posteriores. No fim, todo o negócio sofre. O desafio dos dirigentes é manter todos os envolvidos apenas satisfeitos ou "dentro das suas específicas zonas de tolerância".

\subsubsection{Medidas tradicionais versus medidas equilibradas}

Apesar de o equilíbrio entre os envolvidos ser uma questão, uma outra é o equilíbrio entre as medidas de desempenho financeiras e operacionais e entre a história e o futuro. Kaplan e Norton (1996) indiciam deficiências do tradicional sistema de contabilidade de custos. Os sistemas tradicionais funcionam de acordo com as necessidades do mercado de ações e têm ênfase essencialmente histórica e financeira. Os sistemas modernos precisam ser equilibrados entre o financeiro e o operacional e entre a história e o futuro. Uma maneira de mostrar a ênfase relativa entre as medidas tradicionais e as medidas equilibradas é mostrar as prioridades relativas por meio de círculos nos quais os maiores indicam uma maior prioridade e um maior número de medidas em uso, como mostra a figura 4.

Figura 4 - Prioridades tradicionais e equilibradas

Tradicionais (Passado)

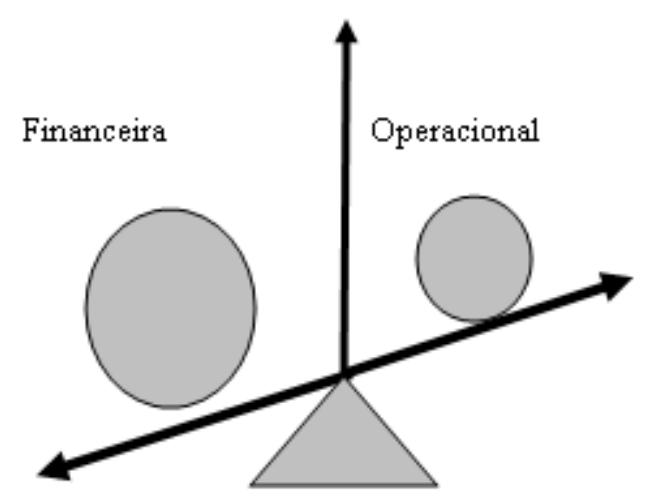

Equilibradas (Futuro)

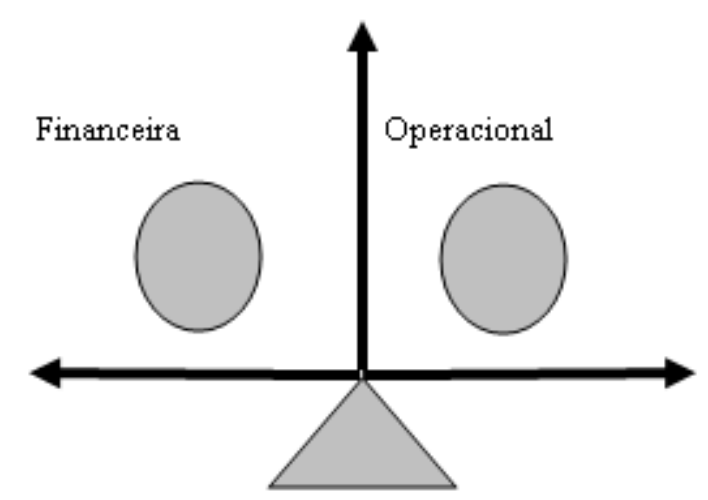

Fonte: Adaptado de Harrison e Hoek, 2003

Ao desenvolver um sistema moderno de mensuração do desempenho, é necessário levar todos esses fatores em consideração e criar um sistema equilibrado de mensuração do desempenho. Esse é o objetivo do "Prisma do Desempenho".

\subsubsection{O prisma do desempenho}

O Prisma do Desempenho (Neely et al., 2000; Neely e Adams, 2000) é uma estrutura que ajuda a lidar com o problema de decidir que medidas de desempenho selecionar para o 
uso dentro de organizações. A estrutura possuiu a forma de um prisma com cinco faces. Ela adota um ponto de vista de mensuração do desempenho centrada no envolvido e, em contrapartida, recebe contribuições deste. Assim, a satisfação do envolvido, isto é, uma visão de que o propósito da empresa é satisfazer os requisitos do envolvido e, em compensação, receber contribuições deste. Assim, a satisfação do envolvido ocupa a face inferior. Entre essas faces, há três mecanismos de facilitação: estratégias, processos e capacidades.

As cinco faces do prisma do desempenho podem ser descritas como segue:

- A face 1 (superior) é chamada de "satisfação dos envolvidos" e trata da pergunta “Quem são os envolvidos, o que eles querem e de que precisam?”.

A face 2 (lateral) é chamada de "estratégias" e trata da pergunta: "Quais são as estratégias que exigimos para assegurar que os desejos e as necessidades dos envolvidos serão satisfeitos?".

- A face 3 (lateral) é chamada de "processos" e faz a pergunta: "Quais são os processos que temos de colocar em funcionamento para permitir que nossas estratégias sejam alcançadas?”. Por “processos” entende-se os processos de negócios necessários para dirigir a organização, inclusive o desenvolvimento de novos produtos e serviços, a geração e o atendimento da demanda, bem como o gerenciamento da empresa.

- A face 4 (lateral) é chamada de "capacidades", que são definidas como a combinação de pessoal, práticas, tecnologia e infra-estrutura que, juntos, possibilitam a execução dos processos de negócios da organização. As capacidades tratam da pergunta: "Quais são as capacidades que exigimos para operar nossos processos?”.

- A face 5 (base) é chamada de "contribuição dos envolvidos". O relacionamento de uma organização com os envolvidos não se limita a satisfazê-los (Face 1); os envolvidos também devem contribuir com a organização. Assim, uma empresa pode satisfazer os funcionários em termos de salário, reconhecimento, emprego, de longo prazo e assim por diante. Mas ela deseja em troca de alguns benéficos, como sugestões de melhoria, fidelidade e que funcionários se 
mantenham atualizados em relação a seus conhecimentos e especialidades. $\mathrm{O}$ Prisma reconhece, portanto, um relacionamento recíproco entre os envolvidos e a organização.

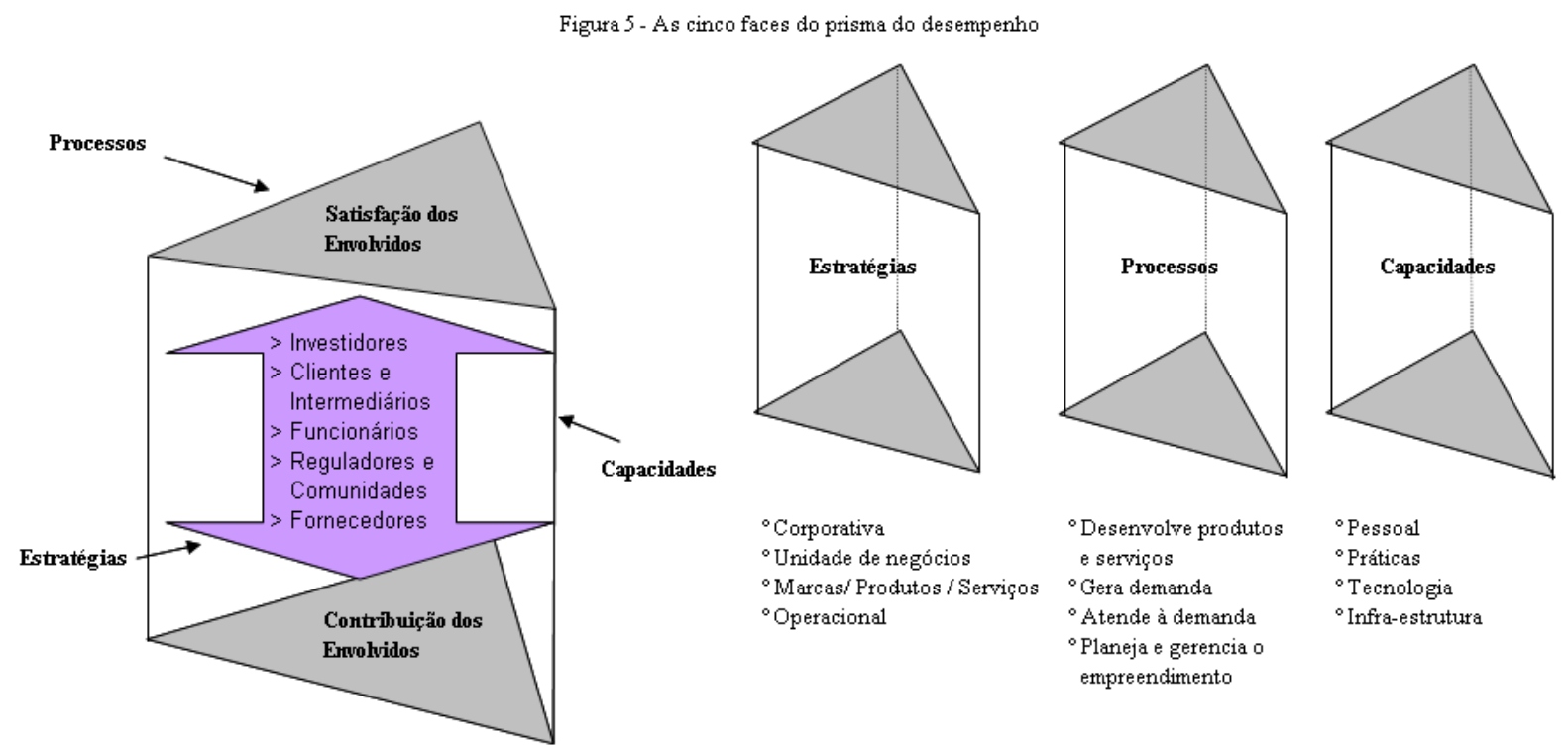

Fonte: Adaptado de Neely et. al., 2000

Cada passo do prisma do desempenho, representado pelas cinco faces listadas acima, exige que as medidas de desempenho sejam estabelecidas para harmonizar todos os aspectos da maneira como a organização é dirigida. $\mathrm{Na}$ (face 1), ampliando os objetivos de desempenho de Slack (1993), existem cinco maneiras de competir por meio da logística. São elas: qualidade; velocidade; tempestividade; flexibilidade e custo. Por exemplo, a velocidade da entrega poderia ser identificada como o critério mais alto de conquista de pedidos de compra. As implicações para as necessidades dos envolvidos são analisadas em termos como:

- Funcionários: consciência e treinamento. Comunicação das medidas de desempenho relativas ao tempo, tais como eficiência de rendimento;

- Clientes: acordo em relação aos objetivos com base no tempo. Sistema de monitoramento claramente compreendido colocado em funcionamento. Acordo sobre os objetivos de melhoria para os três próximos anos;

- Fornecedores: acordo sobre os alvos com base no tempo de entrega e flexibilidade. Objetivos de melhoria de acordo com os objetivos do cliente etc. 
Um processo similar é utilizado para estender as medidas de desempenho pelas outras quatro faces do prisma. Por exemplo, as medidas de satisfação dos funcionários acabam afetando as capacidades necessárias (Face 4). O prisma de desempenho começa a equilibrar e a integrar as medidas de desempenho em aspectos-chave da gestão do negócio. (Harrison e Hoek, 2003).

\subsubsection{O modelo SCOR}

Harrison e Hoek (2003) consideram que o modelo de referência das operações da cadeia de suprimento é o SCOR, do inglês supply chain operations reference.

Este modelo ajuda as empresas a compreender o desempenho e as oportunidades de melhoria de sua cadeia de suprimento. É uma estrutura que perpassa por vários setores e foi desenvolvida pelo Supply Chain Council. Este modelo utiliza uma abordagem baseada em processos da cadeia de suprimento.

O modelo de referência das operações da cadeia de suprimentos (SCOR) fundamentase em quatro processos de gerenciamento distintos. A cadeia de suprimento é vista em termos de processos de gerenciamento que se sobrepõem (obter fonte de suprimento, fazer e entregar) dentro de uma estrutura de planejamento integrada que engloba todas as organizações da cadeia.

A cadeia de suprimento é uma visão baseada em processos que se estendem de um limite organizacional a outro, conforme pode ser visto na figura 6 . 


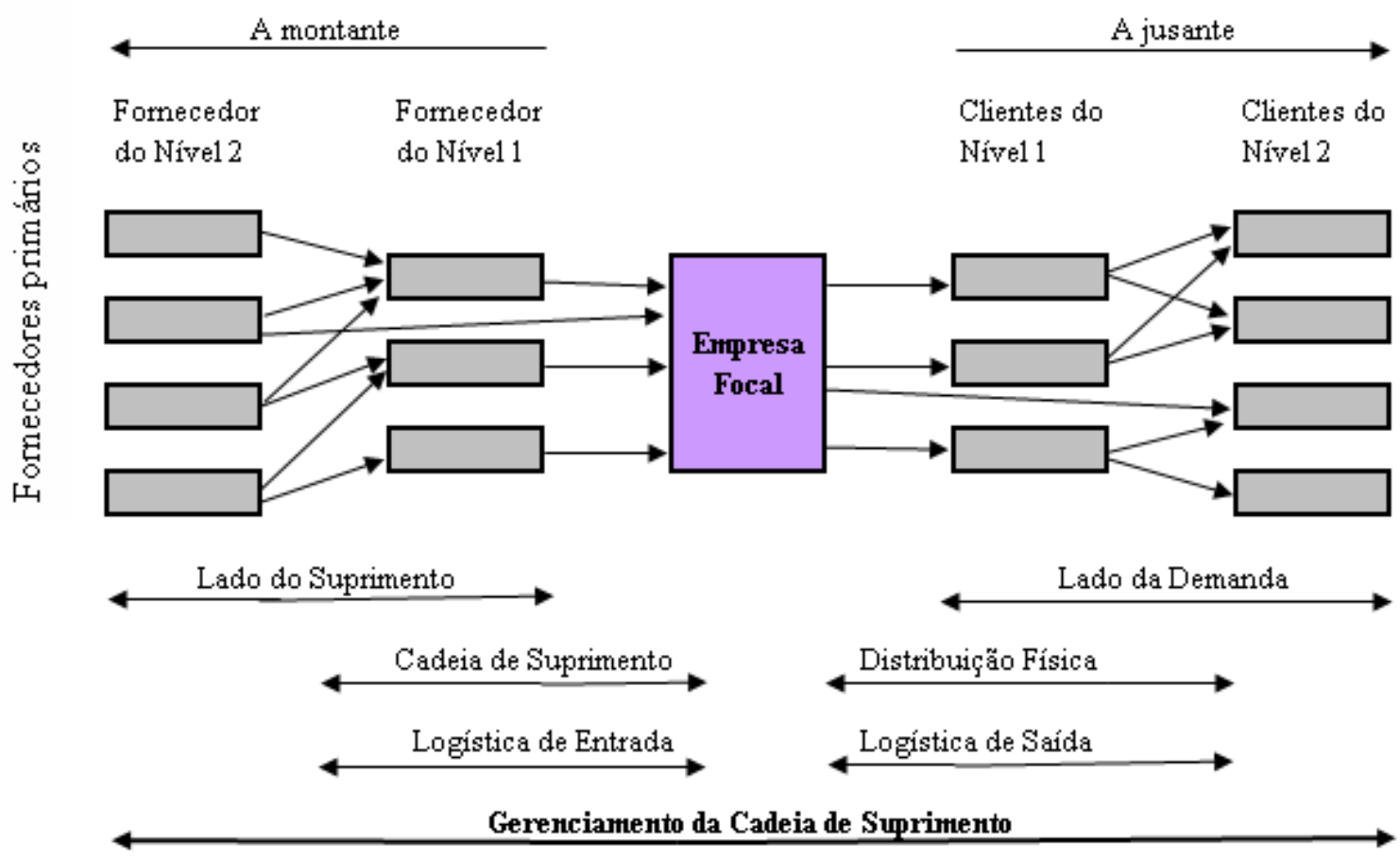

Fonte: Adaptado de Slack et. al., 2007

Os processos de gerenciamento da empresa foco são vistos como se fossem ligados a processos correspondentes dentro das organizações do fornecedor e do cliente. Os quatro processos distintos de gerenciamento podem ser descritos da seguinte forma:

- Planejar: as tarefas de planejamento da demanda e suprimento estabelecidos dentro de um sistema de planejamento geral que cobre atividades como a capacidade de longo prazo e o planejamento de recursos;

- $\quad$ Obter fontes de suprimento: a tarefa de aquisição de materiais estabelecida dentro de um sistema geral de obtenção das fontes de suprimentos, o que inclui atividades como certificação de representantes e contratação de representantes;

Fazer: a tarefa de execução da produção estabelecida dentro de um sistema geral de produção, o que inclui atividades como programação de estações de trabalhos/oficinas;

Entregar: as tarefas do dia-a-dia de gerenciar a demanda, pedidos, armazenagem, transporte, instalações e serviços para funcionamento. Essas tarefas são estabelecidas dentro de um sistema geral de gerenciamento de 
entregas, o que inclui regras de pedidos e o gerenciamento de quantidades de entrega.

Figura 7 - Modelo ilustrativo de medição de desempenho SCOR

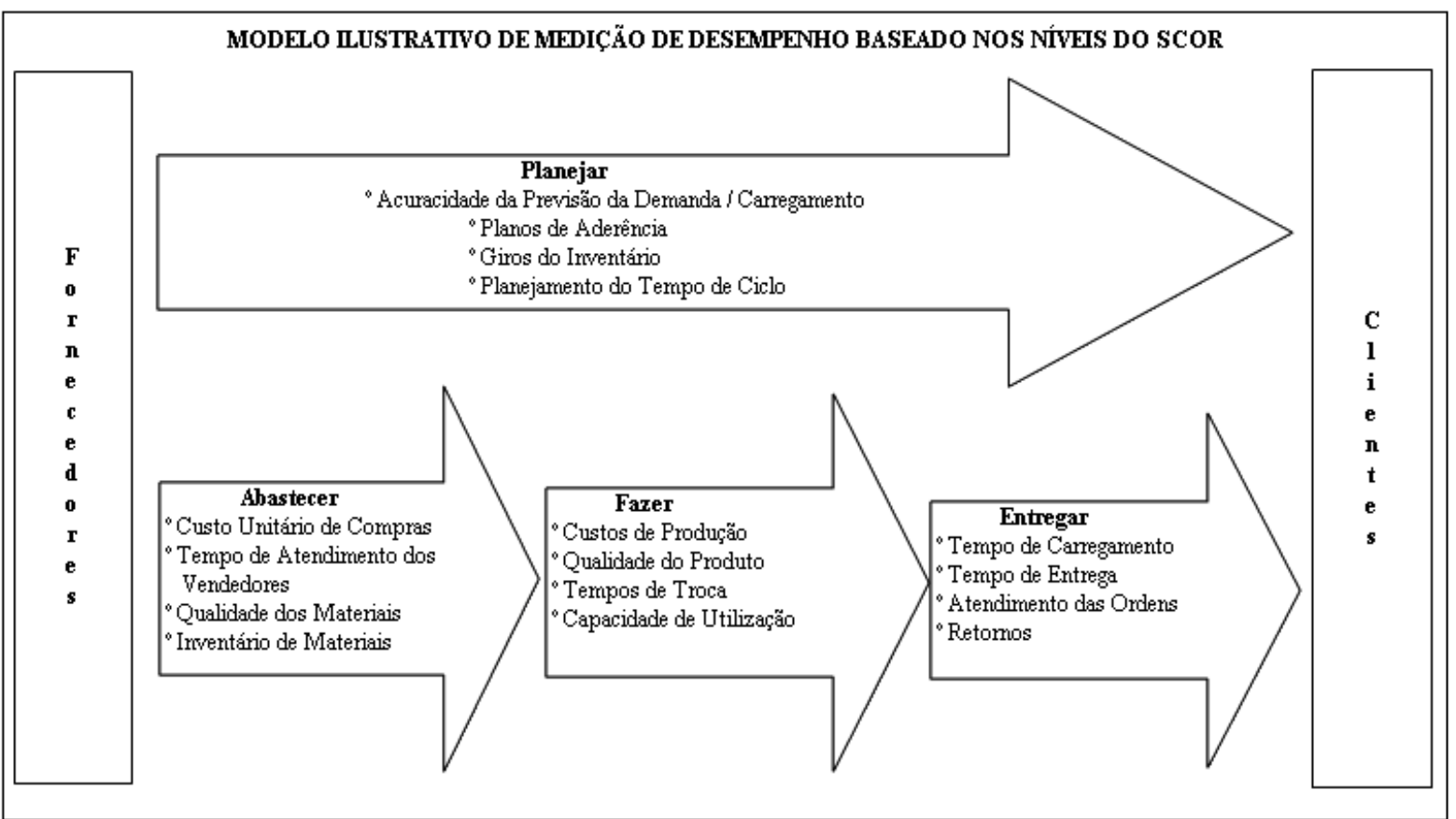

Fonte: Adaptado de Lapide, 2000

O desempenho da cadeia de suprimento está vinculado a medidas que podem ser tabuladas. Existem quatro níveis no modelo SCOR:

- Nível 1: uma ampla definição dos processos de gerenciamento do planejar, obter fontes de suprimentos, fazer e entregar, que é utilizada para estabelecer objetivos competitivos;

- Nível 2: define as principais categorias de processos que são possíveis componentes de uma cadeia de suprimento;

- Nível 3: fornece as informações necessárias para planejar e estabelecer metas para cada elemento que compõem as categorias de nível 2;

- Nível 4: o plano de implementação necessário para colocar as melhorias para funcionar.

Para ilustrar como tais conceitos devem ser aplicados na prática, a tabela 1apresentada a seguir é adaptada do Web site do SCOR. Ela mostra o desempenho real em comparação às 
medidas do SCOR de nível 1 de determinada empresa. Ela também mostra como essas medidas são comparadas com o SCOR em termos do que era necessário para alcançar a paridade com a "população competitiva", do que era necessário para ganhar vantagem e do que era necessário para mostrar um desempenho superior.

Tabela 1 - Avaliação do desempenho da cadeia de suprimento

\begin{tabular}{|c|c|c|c|c|c|c|}
\hline \multicolumn{4}{|c|}{ SCORECARD DA CADEIA DE SUPRIMENT'O v 8.0} & \multicolumn{3}{|c|}{$\begin{array}{l}\text { Desempenho versus p op ulaçă } \\
\text { competiliva }\end{array}$} \\
\hline & Medida geral & $\begin{array}{l}\text { Media do SCOR de } \\
\text { nível l. } \\
\text { Qualidade de entrega } \\
\text { na data combinada }\end{array}$ & $\begin{array}{l}\text { Real } \\
50 \%\end{array}$ & $\begin{array}{l}\text { Paridade } \\
85 \%\end{array}$ & $\begin{array}{l}\text { Vantagem } \\
90 \%\end{array}$ & $\begin{array}{l}\text { Superior } \\
95 \%\end{array}$ \\
\hline \multirow{5}{*}{ Externa } & \multirow{2}{*}{$\begin{array}{l}\text { Confiabilidade } \\
\text { da cadeia de } \\
\text { suprimento }\end{array}$} & $\begin{array}{c}\text { Taxas de pelo } \\
\text { atendimento aos } \\
\text { pedidos }\end{array}$ & $63 \%$ & $94 \%$ & $96 \%$ & $98 \%$ \\
\hline & & $\begin{array}{l}\text { Perfeito atendimento } \\
\text { aos pedidos de compra }\end{array}$ & $0 \%$ & $80 \%$ & $85 \%$ & $90 \%$ \\
\hline & \multirow{3}{*}{$\begin{array}{l}\text { Flexabilidade } \\
\text { e capacidade } \\
\text { de resposta }\end{array}$} & $\begin{array}{l}\text { Tempos de irvestida } \\
\text { w atendimento aos } \\
\text { pedidos de compra } \\
\end{array}$ & 7 dias & 7 dias & 5 dias & 3 dias \\
\hline & & $\begin{array}{c}\text { Flexibilidade da } \\
\text { produção }\end{array}$ & 45 dias & 30 dias & 25 dias & 20 dias \\
\hline & & $\begin{array}{c}\text { Cus tos totais da gestão } \\
\text { logística }\end{array}$ & $19 \%$ & & & \\
\hline \multirow[t]{3}{*}{ Interna } & Custo & $\begin{array}{c}\text { Custos de garantia, } \\
\text { devohuçóes e } \\
\text { descontos/ conces sões. } \\
\text { Valor adicionado pela } \\
\text { produtividade de cada } \\
\text { funcionário } \\
\end{array}$ & $\$ 122 \mathrm{~K}$ & $\$ 156 \mathrm{~K}$ & $\$ 306 \mathrm{~K}$ & $\begin{array}{l}\text { HA } \\
\$ 460 \mathrm{~K}\end{array}$ \\
\hline & \multirow[t]{2}{*}{ Ativos } & $\begin{array}{c}\text { Dias de suprimento de } \\
\text { es toque } \\
\text { Termo de ciclo de } \\
\text { caixa }\end{array}$ & $\begin{array}{l}119 \\
\text { dias } \\
196 \\
\text { dias }\end{array}$ & $\begin{array}{l}55 \text { dias } \\
80 \text { dias }\end{array}$ & $\begin{array}{l}38 \text { dias } \\
46 \text { dias }\end{array}$ & $\begin{array}{l}22 \text { dias } \\
28 \text { dias }\end{array}$ \\
\hline & & $\begin{array}{c}\begin{array}{c}\text { Giro de ativos líquidos } \\
\text { (capital de giro) }\end{array} \\
\end{array}$ & $\begin{array}{c}2,2 \\
\text { giros }\end{array}$ & 8 giros & 12 giros & 19 giros \\
\hline
\end{tabular}

Fonte: Adaptado de Lapide, 2000

Analisando os resultados observa-se que todas as medidas do nível 1 estão abaixo da paridade, exceto os tempos de investida no atendimento aos pedidos. As medidas externas, como desempenho na entrega e o perfeito atendimento aos pedidos, estão seriamente fora de controle. A flexibilidade da produção está muito atrás da população competitiva, sugerindo que o cronograma-mestre é "fixo" para um período demasiadamente longo - e sem dúvida existem causas subjacentes a isso. As medidas internas também não estão em boa forma, com um fraco desempenho de custo e um histórico de utilização de ativos nada competitivo.

3. Proposição de modelo para medição do nível de maturidade do relacionamento entre participantes de uma CS

\subsection{Combinando o prisma do desempenho com o SCOR}


O modelo apresentado na tabela 2, que para efeitos deste estudo chamar-se-á de Matriz de Medição do Nível de Maturidade do Relacionamento entre Participantes de uma CS, foi desenvolvido a partir da revisão na literatura na qual encontram-se modelos de referência que servem para medir o desempenho de uma organização - O Prisma do Desempenho e o modelo de referência que é utilizado para medir o desempenho da cadeia de suprimento ou SCOR. Esta matriz foi desenvolvida com a combinação entre estes modelos, contemplando as dimensões estratégicas, processos e capacidades do Prisma do Desempenho e a forma de medir o desempenho do modelo SCOR. Para a determinação dos níveis de maturidade dos relacionamentos entre participantes de uma cadeia de suprimento, utilizou-se a definição de CS formulada por Bititci et al., (2005), de GCS apresentada por Pires, (2004) e de GCSA desenvolvida a partir da definição de EA formulada por Bititci et al., (2005) e foi criado o modelo abaixo.

Tabela 2 - Matriz de medição de níveis de maturidade de relacionamentos

\begin{tabular}{|c|c|c|c|c|c|}
\hline \multirow{2}{*}{\multicolumn{3}{|c|}{ Matriz - Medição do Nível de Maturidade do Relacionamento (MINMR) }} & \multicolumn{3}{|c|}{ Medida vetsus Nível de Maturidade do Relacionamento } \\
\hline & & & $\begin{array}{l}\text { Cadeia de empresas } \\
\text { individuais. Máximo } \\
\text { desemperho } \\
\text { individual. Sub- } \\
\text { otimização do } \\
\text { desemperho total. } \\
\text { (Nível l) }\end{array}$ & $\begin{array}{c}\text { Modelo gerencial que } \\
\text { busca obter sinergias } \\
\text { através da integração } \\
\text { de processos de } \\
\text { negócios chave ao } \\
\text { longo da CS. } \\
\text { (Nível 2) }\end{array}$ & $\begin{array}{c}\text { Desempenho } \\
\text { individual otimizado. } \\
\text { Máximo desemperho } \\
\text { total. Garhos são } \\
\text { compartilhados entre } \\
\text { as empresas. } \\
\text { (Nível 3) }\end{array}$ \\
\hline & Medida Geral & \multicolumn{2}{|c|}{ Propósito da Medida } & \multicolumn{2}{|c|}{ Avaliação da Medida } \\
\hline \multirow{5}{*}{ Estratégicas } & Corporativa & & & & \\
\hline & Unidade de negócios & & & & \\
\hline & Marcas & & & & \\
\hline & Produtos & & & & \\
\hline & Serviços & & & & \\
\hline \multirow{4}{*}{ Processos } & Deservolve produtos e serviços & & & & \\
\hline & Gera demanda & & & & \\
\hline & Atende à demanda & & & & \\
\hline & Planeja e gerencia o empreendimento & & & & \\
\hline \multirow{4}{*}{ Capacidades } & Pessoal & & & & \\
\hline & Práticas & & & & \\
\hline & Tecrologia & & & & \\
\hline & Infra-estrutura & & & & \\
\hline
\end{tabular}

Fonte: Adaptado de PINHEIRO DE LIMA, E; GOUVEAA DA COSTA, S. E., 2004

\subsection{Análise do modelo proposto}

Os níveis de maturidade dos relacionamentos entre membros de uma CS podem ser identificados através das medidas estratégicas, processos e capacidades. Questionando-se com qual propósito estas foram desenvolvidas, se são compartilhadas ou não, será possível identificar os níveis de maturidade de relacionamento. Como por exemplo, se ao realizar uma pesquisa de campo e como resultado constatar que determinada empresa integrante de uma CS desenvolveu as dimensões anteriormente citadas e não as compartilha com outros membros da CS, poder-se-á considerar que o nível de relacionamento entre estas empresas é 
de nível 1, ou seja, as estratégias, processos e atividades são desenvolvidas visando atender aos interesses individuais da própria empresa.

De nível 2, podem ser considerados os relacionamentos entre empresas participantes de uma CS que não desenvolvem e nem compartilham das medidas estratégicas, porém, integram processos de negócios chave e desenvolvem capacidades em conjunto para dar suporte aos processos de negócios que estão integrados.

De nível 3, podem ser considerados os relacionamentos entre os participantes de uma CS que desenvolvem e compartilham as medidas estratégicas, de processos e de atividades como se estas empresas fossem uma única empresa.

\subsubsection{Nível 1 de maturidade do relacionamento}

Pressupondo-se que ao investigarmos o nível de relacionamento entre determinadas empresas participantes de uma CS encontramos o resultado apresentado na tabela 3 , concluise que o nível de maturidade do relacionamento entre as empresas é de nível 1, ou seja, operam dentro de uma CS como empresas individuais, cujo relacionamento é do tipo clientefornecedor, onde cada participante tenta maximizar seus próprios objetivos, assim subotimizando o desempenho total da cadeia. As medidas estratégicas, os processos e as atividades são desenvolvidos para os propósitos da própria empresa.

Tabela 3 - Matriz de medição de níveis de maturidade de relacionamentos

\begin{tabular}{|c|c|c|c|c|c|c|}
\hline & & & \multicolumn{4}{|c|}{ Medida vetsus Nível de Maturidade do Relacionamento } \\
\hline \multicolumn{3}{|c|}{ Matriz - Medição do Nível de Maturidade do Relacionamento (MNMR) } & \multicolumn{2}{|c|}{$\begin{array}{l}\text { Cadeia de empresas } \\
\text { individuais. Máximo } \\
\text { desempenho individual. } \\
\text { Sub-otimização do } \\
\text { desemperho total. } \\
\text { ( Nível l) }\end{array}$} & $\begin{array}{l}\text { Modelo gerencial que } \\
\text { busca obter sinergias } \\
\text { através da integração de } \\
\text { processos de negócios } \\
\text { chave ao longo da CS. } \\
\text { (Nivel 2) }\end{array}$ & $\begin{array}{l}\text { Desempenho individual } \\
\text { otimizado. Máximo } \\
\text { desemperho total. } \\
\text { Ganhos são } \\
\text { compartillhados entre as } \\
\text { empresas. } \\
\text { (Nivel 3) }\end{array}$ \\
\hline & Medida Geral & \multicolumn{2}{|c|}{ Propósito da Medida } & \multicolumn{3}{|c|}{ Avaliação da Medida } \\
\hline \multirow{5}{*}{ Estratégicas } & Corporativa & \multicolumn{2}{|c|}{ Com qual propósito denservolve elou compartilha? } & \multicolumn{3}{|c|}{ Nível 1 - Individual, voltado para a própria empresa } \\
\hline & Unidade de negócios & \multicolumn{2}{|c|}{ Com qual propósito denservolve elou compartilha? } & \multicolumn{3}{|c|}{ Nível 1 - Individual, voltado para a própria empresa } \\
\hline & Marcas & \multicolumn{2}{|c|}{ Com qual propósito denservolve elou compartilha? } & \multicolumn{3}{|c|}{ Nível 1 - Individual, voltado para a própria empresa } \\
\hline & Produtos & \multicolumn{2}{|c|}{ Corn qual propósito denservolve elou compartilha? } & \multicolumn{3}{|c|}{ Nível 1 - Individual, voltado para a própria empresa } \\
\hline & Serviços & \multicolumn{2}{|c|}{ Com qual propósito denservolve elou compartilha? } & \multicolumn{3}{|c|}{ Nível 1 - Individual, voltado para a própria empresa } \\
\hline \multirow{4}{*}{ Processos } & Deservolve produtos e serviços & \multicolumn{2}{|c|}{ Com qual propósito denservolve? } & \multicolumn{3}{|c|}{ Nível 1 - Individual, voltado para a própria empresa } \\
\hline & Gera demanda & \multicolumn{2}{|c|}{ Com qual propósito denservolve? } & \multicolumn{3}{|c|}{ Nível 1 - Individual, voltado para a própria empresa } \\
\hline & Atende à demanda & \multicolumn{2}{|c|}{ Com qual propósito denservolve? } & \multicolumn{3}{|c|}{ Nível 1 - Individual, voltado para a própria empresa } \\
\hline & Planeja e gerencia o empreendimento & \multicolumn{2}{|c|}{ Com qual propósito denservolve? } & \multicolumn{3}{|c|}{ Nível 1 - Individual, voltado para a própria empresa } \\
\hline \multirow{4}{*}{ Capacidades } & Pessoal & \multicolumn{2}{|c|}{ Com qual propósito denservolve elou compartilha? } & \multicolumn{3}{|c|}{ Nível 1 - Individual voltado para a própria empresa } \\
\hline & Práticas & \multicolumn{2}{|c|}{ Com qual propósito denservolve elou compartilha? } & \multicolumn{3}{|c|}{ Nível 1 - Individual, voltado para a própria empresa } \\
\hline & Tecnologia & \multicolumn{2}{|c|}{ Com qual propósito denservolve elou compartilha? } & \multicolumn{3}{|c|}{ Nível 1 - Individual, voltado para a própria empresa } \\
\hline & Infra-estrutura & \multicolumn{2}{|c|}{ Com qual propósito denservolve elou compartilha? } & \multicolumn{3}{|c|}{ Nível 1 - Individual, voltado para a própria empresa } \\
\hline
\end{tabular}




\subsubsection{Nível 2 de maturidade do relacionamento}

Pressupondo-se que ao investigarmos o nível de relacionamento entre determinadas empresas participantes de uma CS encontramos o resultado apresentado na tabela 4, concluise que o nível de maturidade do relacionamento entre as empresas é de nível 2, ou seja, os participantes adotam um modelo gerencial que busca obter sinergias através da integração dos processos de negócios chaves, cujo objetivo principal é atender ao consumidor final e outros stakeholders da forma mais eficaz e eficiente possível, com produtos e/ou serviços de maior valor percebido pelo cliente final, ao menor custo possível. As medidas estratégicas são desenvolvidas para atender aos propósitos da própria empresa. Já, os processos de negócios chave e as atividades são voltados para atender os propósitos da cadeia.

Tabela 4 - Matriz de medição de núveis de maturidade de relacionamentos

\begin{tabular}{|c|c|c|c|c|c|}
\hline & & & \multicolumn{3}{|c|}{ Medida versus Nível de Maturidade do Relacionamento } \\
\hline \multicolumn{3}{|c|}{ Matriz - Medição do Nível de Maturidade do Relacionamento (MNMR) } & $\begin{array}{l}\text { Cadeia de empresas } \\
\text { indrividuais. Máximo } \\
\text { desermpenho individua } \\
\text { Sub-otimização do } \\
\text { desempenho total. } \\
\text { (Nivel l) }\end{array}$ & \begin{tabular}{l|c} 
Ms & Modelo gerencial que \\
no & busca obter sinergias \\
ual. & através da integração de \\
0 & processos de negócios \\
l. & chave ao longo da CS. \\
(Nível 2)
\end{tabular} & $\begin{array}{l}\text { Desemperho individual } \\
\text { otimizado. Máximo } \\
\text { desemperho total. } \\
\text { Garhos são } \\
\text { compartilhados entre as } \\
\text { empresas. } \\
\text { (Nivel 3) }\end{array}$ \\
\hline & Medida Geral & \multicolumn{2}{|c|}{ Propósito da Medida } & \multicolumn{2}{|c|}{ Avaliação da Medida } \\
\hline \multirow{5}{*}{ Estratégicas } & Corporativa & \multicolumn{2}{|c|}{ Com qual propósito denservolve elou compartilha? } & \multicolumn{2}{|c|}{ Nível 1 - Individual, voltado para a própria empresa } \\
\hline & Unidade de negócios & \multicolumn{2}{|c|}{ Com qual propósito denservolve elou compartilha? } & \multicolumn{2}{|c|}{ Nível 1 - Individual, voltado para a própria empresa } \\
\hline & Marcas & \multicolumn{2}{|c|}{ Com qual propósito denservolve elou compartilha? } & \multicolumn{2}{|c|}{ Nível 1 - Individual, voltado para a própria empresa } \\
\hline & Produtos & \multicolumn{2}{|c|}{ Com qual propósito denservolve elou compartilha? } & \multicolumn{2}{|c|}{ Nível 1 - Individual, voltado para a própria empresa } \\
\hline & Serviços & \multicolumn{2}{|c|}{ Com qual propósito denservolve elou compartilha? } & \multicolumn{2}{|c|}{ Nível 1 - Individual voltado para a própria empresa } \\
\hline \multirow{4}{*}{ Processos } & Deservolve produtos e serviços & \multicolumn{2}{|c|}{ Com qual propósito denservolve? } & \multicolumn{2}{|c|}{ Nível 2 - Integrar processos de negócio chave } \\
\hline & Gera demanda & \multicolumn{2}{|c|}{ Com qual propósito denservolve? } & \multicolumn{2}{|c|}{ Nível 2 - Integrar processos de negócio chave } \\
\hline & Atende à demanda & \multicolumn{2}{|c|}{ Com qual propósito denservolve? } & \multicolumn{2}{|c|}{ Nível 2 - Integrar processos de negócio chave } \\
\hline & Planeja e gerencia o empreendimento & \multicolumn{2}{|c|}{ Com qual propósito denservolve? } & \multicolumn{2}{|c|}{ Nível 2 - Integrar processos de negócio chave } \\
\hline \multirow{4}{*}{ Capacidades } & Pessoal & \multicolumn{2}{|c|}{ Com qual propósito denservolve elou compartilha? } & \multicolumn{2}{|c|}{ Nível 2 - Integrar processos de negócio chave } \\
\hline & Práticas & \multicolumn{2}{|c|}{ Com qual propósito denservolve elou cormpartilha? } & \multicolumn{2}{|c|}{ Nível 2 - Integrar processos de negócio chave } \\
\hline & Tecnologia & \multicolumn{2}{|c|}{ Com qual propósito denservolve elou compartilha? } & \multicolumn{2}{|c|}{ Nível 2 - Integrar processos de negócio chave } \\
\hline & Infra-estrutura & \multicolumn{2}{|c|}{ Com qual propósito denservolve elou compartilha? } & \multicolumn{2}{|c|}{ Nível 2 - Integrar processos de negócio chave } \\
\hline
\end{tabular}

Fonte: Adaptado de PINHEIRO DE LIMA, E; GOUVEA DA COSTA, S. E., 2004

\subsubsection{Nível 3 de maturidade do relacionamento}

Pressupondo-se que ao investigarmos o nível de relacionamento entre determinadas empresas participantes de uma CS encontrarmos o resultado apresentado na tabela 5, concluise que o nível de maturidade do relacionamento entre as empresas é de nível 3, ou seja, operam em uma cadeia de empresas que se comportam essencialmente como uma única empresa que tenta maximizar os objetivos corporativos, assim otimizando o desempenho de cada empresa individual. As medidas estratégicas, os processos de negócio e as atividades são 
desenvolvidos com o propósito de maximizar o desempenho total como se fosse uma empresa única.

Tabela 5 - Matriz de medição de níveis de maturidade de relacionamentos

\begin{tabular}{|c|c|c|c|c|c|}
\hline & & & \multicolumn{3}{|c|}{ Medida versus Nível de Maturidade do Relacionamento } \\
\hline \multicolumn{3}{|c|}{ Matriz - Medição do Nível de Maturidade do Relacionamento (MNMR) } & $\begin{array}{l}\text { Cadeia de empresa } \\
\text { individuais. Máxim } \\
\text { desempenho individu } \\
\text { Sub-otimização do } \\
\text { desempenho total } \\
\text { ( Nível l) }\end{array}$ & $\begin{array}{l}\text { Modelo gerencial que } \\
\text { busca obter sinergias } \\
\text { através da integração de } \\
\text { processos de negócios } \\
\text { chave ao longo da CS. } \\
\text { ( Nível 2) }\end{array}$ & $\begin{array}{l}\text { Desempenho individual } \\
\text { otimizado. Máximo } \\
\text { desempenho total. } \\
\text { Ganhos são } \\
\text { compartillhados entre as } \\
\text { empresas. } \\
\text { (Nivel 3) }\end{array}$ \\
\hline & Medida Geral & \multicolumn{2}{|c|}{ Propósito da Medida } & \multicolumn{2}{|c|}{ Avaliação da Medida } \\
\hline \multirow{5}{*}{ Estratégicas } & Corporativa & \multicolumn{2}{|c|}{ Com qual propósito denservolve elou compartilha? } & \multicolumn{2}{|c|}{ Nível 2 - Maximizar o desemperho total da CS } \\
\hline & Unidade de negócios & \multicolumn{2}{|c|}{ Com qual propósito denservolve elou compartilha? } & \multicolumn{2}{|c|}{ Nível 2 - Maximizar o desempenho total da CS } \\
\hline & Marcas & \multicolumn{2}{|c|}{ Com qual propósito denservolve elou compartilha? } & \multicolumn{2}{|c|}{ Nível 2 - Maximizar o desempenho total da CS } \\
\hline & Produtos & \multicolumn{2}{|c|}{ Com qual propósito denservolve elou compartilha? } & \multicolumn{2}{|c|}{ Nível 2 - Maximizar o desemperho total da CS } \\
\hline & Serviços & \multicolumn{2}{|c|}{ Com qual propósito denservolve elou compartilha? } & \multicolumn{2}{|c|}{ Nível 2 - Maximizar o desermperho total da CS } \\
\hline \multirow{4}{*}{ Processos } & Deservolve produtos e serviços & \multicolumn{2}{|c|}{ Com qual propósito denservolve? } & \multicolumn{2}{|c|}{ Nível 2 - Maximizar o desempenho total da CS } \\
\hline & Gera demanda & \multicolumn{2}{|c|}{ Com qual propósito denservolve? } & \multicolumn{2}{|c|}{ Nível 2 - Maximizar o desempenho total da CS } \\
\hline & Atende à demanda & \multicolumn{2}{|c|}{ Com qual propósito denservolve? } & \multicolumn{2}{|c|}{ Nível 2 - Maximizar o desemperho total da CS } \\
\hline & Planeja e gerencia o empreendimento & \multicolumn{2}{|c|}{ Com qual propósito denservolve? } & \multicolumn{2}{|c|}{ Nível 2 - Maximizar o desemperho total da CS } \\
\hline \multirow{4}{*}{ Capacidades } & Pessoal & \multicolumn{2}{|c|}{ Com qual propósito denservolve elou compartilha? } & \multicolumn{2}{|c|}{ Nível 2 - Maximizar o desemperho total da CS } \\
\hline & Práticas & \multicolumn{2}{|c|}{ Com qual propósito denservolve elou compartilha? } & \multicolumn{2}{|c|}{ Nível 2 - Maximizar o desemperho total da CS } \\
\hline & Tecnologia & \multicolumn{2}{|c|}{ Com qual propósito denservolve elou compartilha? } & \multicolumn{2}{|c|}{ Nível 2 - Maximizar o desemperho total da CS } \\
\hline & Infra-estrutura & \multicolumn{2}{|c|}{ Com qual propósito denservolve elou compartilha? } & \multicolumn{2}{|c|}{ Nível 2 - Maximizar o desemperho total da CS } \\
\hline
\end{tabular}

Fonte: Adaptado de PINHEIRO DE LIMA, E; GOUVEA DA COSTA, S. E., 2004

\section{Conclusões e recomendações}

A revisão na literatura sobre as definições de CS, GCS, EA e GCSA, propiciou a análise da evolução do nível de relacionamento dos participantes de uma cadeia de suprimento.

Para os propósitos deste estudo, considerou-se que no nível 1 desta evolução, estão as empresas que operam em conformidade com a definição de CS, ou seja, fazem parte de uma cadeia cujo relacionamento é de comprador-fornecedor onde cada empresa busca alcançar objetivos individuais, assim sub-otimizando o desempenho total da cadeia. No nível 2 estão as empresas que operam em conformidade com a definição de GCS, ou seja, relacionam-se integrando processos de negócio chave. No nível 3 encontram-se as empresas que operam em conformidade com o conceito de EA, ou seja, relacionam-se integralmente como se fosse uma única empresa. Deste modo, maximizam o desempenho total e os ganhos são compartilhados entre as empresas. 
A partir da revisão na literatura sobre medição do desempenho, o Prisma do Desempenho e o SCOR, foi possível desenvolver uma matriz combinando as chamadas faces estratégicas, processos e capacidades do modelo do Prisma do Desempenho com a forma de tabulação de dados do modelo SCOR. Deste modo, foi desenvolvido e analisado o modelo proposto na inicial, para assim, identificar-se o nível de maturidade do relacionamento entre participantes de uma CS.

Diante dos resultados obtidos, recomenda-se que para continuidade deste trabalho de pesquisa, inicialmente sejam desenvolvidos novos indicadores de medição de nível de maturidade de relacionamento entre empresas contratantes e contratadas para fornecimento de produtos e/ou serviços e posteriormente, testar o modelo através de pesquisa de campo.

Outrossim, este trabalho de pesquisa também poderá despertar nos pesquisados o interesse em conhecer as ações que são necessárias para a evolução de empresas participantes de uma cadeia de suprimento, ou seja, evoluir da condição de simples participante de uma cadeia de suprimento (CS) ao conceito de Empresa Ampliada (EA).

\begin{abstract}
Nowadays, the competitivity between enterprises is presented inside the supply chain. The strategic integration of processes and activities between the supply chain members become key factors of success. Based on the logistics conceptual evolution the evolution of the relationships between the members of a supply chain is obtained. Combining systems performance measuring models, a matrix that will be able to be used to measure the relationship maturity levels between participants of a supply chain was developed. This paper presents a conceptual theoretic contribution, proposing a referential model for the analysis of the maturity levels of the relationship between members of a supply chain. The referential model combines performance measuring systems and establishes as maturity levels the definitions of Supply Chain (SC), Supply Chain Management (SCM) and Extended Supply Chain Management (ESCM), formulated from the definition of Extended Enterprise (EE).
\end{abstract}

Keywords: logistics conceptual evolution; performance measuring systems; relationship maturity level; Extended Supply Chain Management.

\title{
Referências
}

BALLOU, R. H. Gerenciamento da cadeia de suprimentos / logística empresarial. Porto Alegre: Bookman, 2001.

BALLOU, R. H. Logística empresarial: transportes, administração de materiais e distribuição física - São Paulo: Atlas 1993. 
BINDER, M.; CLEGG, B. Enterprise management: A new frontier for organizations. International Journal of Production Economics. n.106, p. 409-430. 2007.

cross ref

BITITCI, U. S.; MENDIBIL, K.; MARTINEZ, V.; ALBORES, P. Measuring and managing performance in extended enterprises. International Journal of Operations \& Production Management. v. 25, n. 4, p. 333 - 353 , 2005.

cross'

BOURNE, M.; NEELY, A.; Mills, J.; PLATTS, K. Implementing performance measurement systems: a literature review. International Journal of Business Performance Management, v. 5, n. 1, p. 1-24, 2003.

cross ${ }^{\text {ref }}$

BOYSON, S. Logistics and the extended enterprise. New York: John Wiley, 1999.

BROWNE, J.; ZHANG, J. Extended and virtual enterprises: similarities and differences. International Journal of Agile Management Systems. 1/1 p. 30 -36, 1999.

cross'

CHRISTOPHER, M. Logistics and supply chain management. London: Pitman, 1992.

CHRISTOPHER, M. A logística e gerenciamento da cadeia de suprimentos: Estratégia para redução de custos e melhoria dos serviços. São Paulo: Pioneira Thomson Learning, 2001.

CHRISTOPHER, M. A logística do marketing: Otimizando processos para aproximar fornecedores e clientes. São Paulo: Futura, 2002.

CHILDE, S.J. The extended enterprise: a concept for co-operation. Production Planning and Control. v. 9, n. 4, p. 320-7. 1998.

cross ${ }^{\text {ref }}$

COOPER, M. C.; LAMBERT. D. M.; PAGH, J. D. Supply chain management: more than a new name for logistics. The Ohio State Unversity: v. 8, n. 1, 1997.

DOYLE, P. Marketing management and strategy. New York: Printice Hall. 1994.

FLEURY, P. F.; FIGUEIREDO, K. F.; WANKE, P. Logística empresarial: a perspectiva Brasileira. Coleção COPPEAD de Administração. São Paulo: Editora Atlas, 2000.

HARRISON, A.; HOEK, Remko Van. Estratégia e gerenciamento de logística. São Paulo: Futura, 2003.

KAPLAN, R.; NORTON, D. Using the balanced scorecard as a strategic management system. Harvard Business Review, p. 75-85, jan./feb. 1996.

KOCHHAR, A.; ZHANG, Y. A framework for performance measurement in virtual enterprises: proceedings of the 2nd international workshop on performance measurement, Hanover. p. 2-11, 2002.

LAMBERT, D. M.; COOPER, M. C., PAGH, J. D. Supply chain management: Implementation issues and research opportunities. The Ohio State Unversity, v. 9, n. 2, 1998.

LAPIDE, L. What about meansuring supply chain performance? SC Excellence Through Technology Journal, 2000.

LILLEHAGEN, F.; KARLSEN, D. Visual extended enterprise engineering and operation-embedding knowledge management and work execution. Production Planning and Control, v. 12, n. 2, p. 164-75. 2001. cross ${ }^{\text {ref }}$

MARTINEZ, M.T., FOULETIER, K.H.; FAVREL, J. Virtual enterprise: organisation, evolution and control. International Journal of Production Economics. v. 74, p. 225-38, 2001.

cross ${ }^{\text {ref }}$ 
MENTEZER et al. Defining supply chain management. Journal of Business Logistics, v. 22, n. $2,2001$.

NEELY, A.; ADAMS, C. A. Perspectives on performance: The prism. Center for Business Performance, Cranfield School of Management. 2000.

NEELY, A.; MILlS, J.; PLATTS, K. R. H.; GREGORY, M.; BOURNE, M. e KENNERLEY, M. Performance measurement system design: developing and testing a process-based approach. International Journal of Operations and Production Management. v. 20, n. 10, p. 1119-1145, 2000.

NEELY A.; GREGORY, M.; PLATTS, K. Performance measurement system design: A literature review and research agenda. International Journal of Operations \& Production Management. ABI/INFORM Global, 25, 12; p. 1228-1263, 2005.

NOVAES, A. G. Logística e o gerenciamento da cadeia de distribuição: estratégia, operações e avaliação. Rio de Janeiro: Campus, 2001.

O'NEILL, H.; SACKETT, P. The extended manufacturing enterprise paradigm. Management Decision. v. 32, n. 8, p. 42-9, 1994.

PINHEIRO DE LIMA, E; GOUVÊA DA COSTA, S. E. As racionalidades para projeto organizacional no contexto da gestão de operações. Produto \& Produção, vol. 7, n. 1, p. 37-52, mar. 2004.

PIRES, S. Gestão da cadeia de Suprimentos (supply chain management): conceitos, estratégias, práticas e casos, $1^{\mathrm{a}}$ Ed, São Paulo: Atlas, 2004.

SLACK, N.; CHAMBERS, S.; JOHNSTON, R. Administração da produção. $2^{\text {a }}$ ed. São Paulo: Atlas, 2007

SLACK, N.; CHAMBERS, S.; HARLAND, C.; HARRISON, A. \& JOHNSTON, R. Operations Management. Londres: Pitman, 1998.

SLACK, N. Vantagem competitiva em manufatura. São Paulo: Atlas, 1993.

YEE, C.L.; PLATTS, K. W. A framework and tool for supply network strategy operationalisation. International Journal of Production Economics. 104, p. 230-248, 2006.

cross ${ }^{\text {ref }}$

\section{Dados dos autores:}

Nome completo: Gilberto Zanoni

Filiação Institucional: Pontifícia Universidade Católica do Paraná - PUCPR - Curitiba Paraná - Brasil

Departamento: Programa de Pós-Graduação em Engenharia de Produção e Sistemas PPGEPS

Endereço: Rua Celeste Santi, 260 - Bairro Ahú - Curitiba - Paraná - Brasil - CEP 80.530370

Telefone: (41) 3254-6721

e-mail: zanoni@superig.com.br

Nome completo: Dr. Eng. - Edson Pinheiro de Lima 
Filiação Institucional: Pontifícia Universidade Católica do Paraná - PUCPR - Curitiba Paraná - Brasil

Departamento: Programa de Pós-Graduação em Engenharia de Produção e Sistemas PPGEPS

Cargo: Professor

Endereço: Rua Imaculada Conceição, 1155 - Bairro Prado Velho - Curitiba - Paraná - Brasil

- CEP 80.215-901

Parque Tecnológico - Bloco III - $2^{\circ}$ Andar

Telefone: (41) 3271-2579

e-mail: e.pinheiro@pucpr.br

Nome completo: Dr. Eng. - Sérgio Eduardo Gouvêa da Costa

Filiação Institucional: Pontifícia Universidade Católica do Paraná - PUCPR - Curitiba Paraná - Brasil

Departamento: Programa de Pós-Graduação em Engenharia de Produção e Sistemas PPGEPS

Cargo: Professor

Endereço: Rua Imaculada Conceição, 1155 - Bairro Prado Velho - Curitiba - Paraná - Brasil

- CEP 80.215-901

Parque Tecnológico - Bloco III - $2^{\circ}$ Andar

Telefone: (41) 3271-2579

e-mail: s.gouvea@pucpr.br 